\title{
MIS is an Effective Tool to Decision Making
}

\author{
K P Tripathi \\ Lecturer \\ Bharati Vidyapeeth University \\ Institute of Management, Kolhapur, India
}

\begin{abstract}
Management Information System (MIS) has played an important role in the organization from last two decades by providing the information generation tool. It also helps the top management in decision making in crucial business decisions. Businesses in the developed countries are of dynamic nature and it has to get the information from all sources with minimum time and with most proper way having maximum good characteristics of information. The Indian business scenario is also changing at a very fast rate in all the aspects and in all the areas, using advanced software tools like MIS, DSS and Expert System.

MIS provides regular information to managers to allow them to make decisions based on data rather than guesses. Certain data and analysis can play a very useful role in making good decisions about where and when to use human and other resources to achieve the mission of an organization. Managers with quality MIS are able to make decisions from an informed stance rather than a haphazard one. This paper is an attempt to design and develop an MIS for the business organization and show how it helps in taking management decisions related to management function especially for the top management.
\end{abstract}

\section{Keywords}

Management Information System, Transaction Processing System, Decision Support System, MIS Model.

\section{INTRODUCTION}

The Management Information System is a collection of men, tools, procedures and software to perform various business tasks at various levels in the organization. Many organizations have separate MIS departments which are involved in maintaining records, performing transactions, report generations and consolidation of the important information which will be supplied to the various levels of the management. MIS has three basic levels: operational, middle management and top management where the information is passed from bottom to top. This paper is an attempt to design and develop the model of MIS for Birla Corporation Limited, which involves Attendance Capturing \& Recording System which will be used in monitoring the staff, control over the irregularities and reporting to the top management and show how it is useful in decision making at top level. [11]

\section{PROBLEM STATEMENT}

The researcher has proposed the study on 'MIS is an Effective Tool to decision making' with respect to Birla Corporation Limited. The selected organization is of a large scale in terms of size, area and manpower requirement. After preliminary study it was felt to develop an advanced information management system for various functionalities specifically maintaining attendance by computerized methods and generating management information reports for top management and middle level management.

\section{REVIEW OF LITERATURE}

$\mathrm{T}$. Lucey in the book entitled 'Management Information Systems' defines MIS as a system to convert data from internal and external sources into information and to communicate that information is an appropriate form to managers at all levels in all functions to enable them to make timely and effective decisions for planning, directing and controlling the activities for which they are responsible. [5]

Barry E. Cushing in the book entitled 'Accounting Information Systems and Business Organizations' suggests the definition of MIS as a set of human and capital resources within an organization which is responsible for the collection and processing of data to produce information which is useful to all levels of management in planning and controlling the activities of the organization. [5]

The Management Information System (MIS) has evolved as an important tool and technique in business management area in the current opportunities and business threats. Right information at right time in right format will decide the managements' Human resource decisions. MIS is one of the important functions of management. In the $21^{\text {st }}$ century the organizations need the information which is accurate, timely and reliable. The MIS plays an important role in providing the information required for crucial decision making which affects directly to the performance of the organization. [8] [11]

\section{CONCEPT AND MEANING OF MIS}

The initial concept of MIS was to process data from the organization and presents it in the form of reports at regular intervals. The system was largely capable of handling the data from collection to processing. It was more impersonal, requiring each individual to pick and choose the processed data and use it for his requirements. The MIS differs since the people in two organizations involved in the same business. The MIS is for the people in the organization. The MIS model may be the same but it differs greatly in the contents.

The MIS, therefore, is a dynamic concept subject to change, time and again, with a change in the business management process. It continuously interacts with the internal and the external environment of the business and provides a corrective mechanism in the system so that the change needs of information are with effectively. [12]

MIS has been understood and described in a number of ways. It is also popularly known as the Information System, the 
Information and Decision System, the Computer-based Information System. The MIS has more than one definition, some of which are given below:

1. The MIS is defined as a system which provides information support for decision making in the organization.

2. The MIS is defined as an integrated system of man and machine for providing the information to support the operations, the management and the decision making function in the organization.

3. The MIS is defined as a system based on the database of the organization evolved for the purpose of providing information to the people in the organization.

4. The MIS is defined as a Computer based Information System.

Thought there are a number of definitions, all of them converge on one single point, i.e., the MIS is a system to support the decision making function in the organization. [12]

The MIS is defined as an integrated system of man and machine for providing the information to support the operations, the management, and the decision-making function in the organization.

The above definition emphasizes an association between MIS and decision-making. Application software that processes data, which is not used for decision-making, cannot be called an MIS. For instance, a computer-aided design system is not an MIS.

An MIS deals with information that is systematically and routinely collected in accordance with a well-defined set of rules. In other words, data collection is a planned activity for which resources are allocated and rules are defined. [8]

\subsection{The Information Needs of Managers}

The common need basic to all managers is an understanding of the purpose of the organization, its policies, programs, plans and goals though the decisions may be according to the capacity of analytical approach of using the information of the manager the information people need depends on type of decision- structured or unstructured, organizational level they occupy and activities they perform, factors critical to their success.

Figure 1: MIS and Decision Making Process

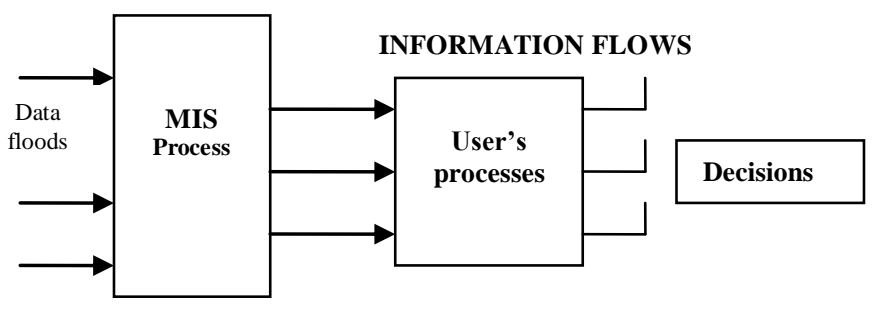

\subsection{Properties of the Needed Information}

As a general rule the more information serves to eliminate the uncertainty in decision-making. Some of the properties of good information are:

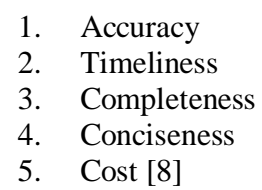

\subsection{Features of MIS}

1. In any organization managers will have varieties of task to manage. MIS is mainly designed to take care of the needs of the managers in the organization.

2. Organizations will have different departments like marketing, production, sales, inventory, maintenance etc. Each of these departments function individually and also in relationship with other departments. Information is available in abundance. MIS aids in integrating the information generated by various departments of the organizations.

3. MIS also helps in establishing mechanism to eliminate redundancies in data.

4. MIS as a system can be broken down into sub system; each sub system may be programmed. This results in easy access of data, accuracy of data and information. It helps in maintaining the consistency of data.

\subsection{Necessity of MIS}

Managers play a key role in any organization. They are responsible for taking decisions appropriate to the need of the market. Information systems have become the main tool used by managers in decision making. Mangers perceive information as the driving force to achieve success in any business. Hence there is a need of MIS. The impact of MIS on the functions is in its management. With a good support, the management of marketing, finance, production and personnel become more efficient. A well designed system with a focus on the manager makes an impact on the managerial efficiency. The impact is on the managerial ability to perform. It improves the decision making ability considerably.

\subsection{Classification of MIS}

There are various types of management information systems. Mason and Swanson (1981) describe four categories of management information systems: (1) Databank information system, (2) Predictive information system, (3) Decision-making information system, and (4) Decision-taking information system. The classification is based on the level of support that the information system provides in the process of decision making. Sachdeva (1990) comprehensively presents these four types of systems:

4.5.1 Databank Information System: The responsibility of this information system is to observe, classify, and store any item of data which might be potentially useful to the decision maker. Each of these databases can be summarized and converted to single tabular presentations of information of interest to management. When information from two or more time periods is compared, trends can be observed.

4.5.2 Predictive Information System: This system moves beyond pure data collection and the determination of trends over time. Predictive information systems provide for the 
drawing of inferences and predictions that are relevant to decision making.

Information obtained from these kinds of analyses is normally summarized in a two-way tabular format. And likewise, the information often is compared over time. Managers can then use such information to make predictions, for example to forecast costs of particular undertakings for budgeting purposes or as a basis for predicting results if a given change is made, such as change in the number of demonstrations with a given change in staffing.

Figure 2: Role of information in the decision process

\section{DECISION STAGE INFORMATION REQUIRED}

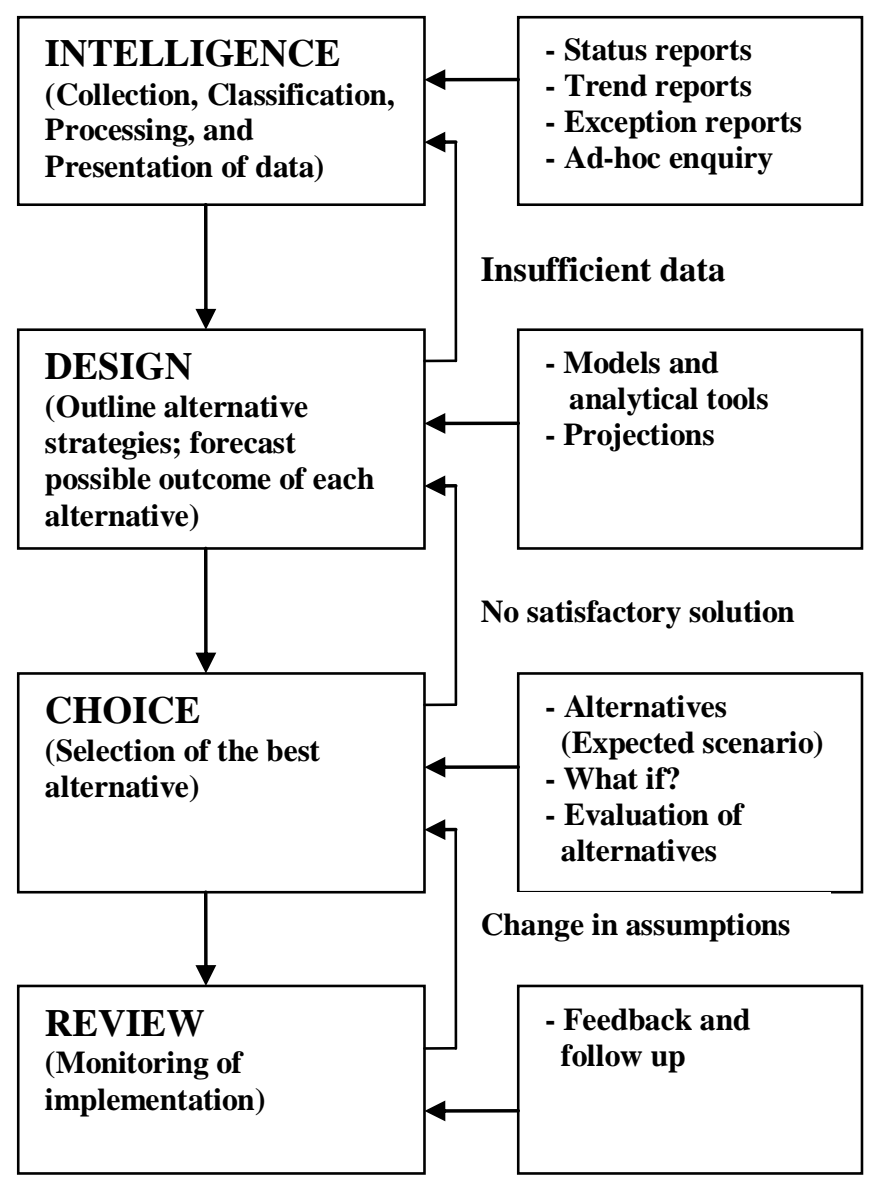

4.5.3 Decision-Making Information System: This system goes one step further in the process of decision making and incorporates the value system of the organization or its criteria for choosing among alternatives.

4.5.4 Decision-Taking Information System: This is a decision system in which the information system and the decision maker are one and the same. Management is so confident in the assumptions incorporated in the system that it basically relegates its power to initiate action to the system itself. Airplanes carry automatic pilot systems, which are an example of a decision-taking system. Once activated, the system itself keeps the plane on course and at the proper speed and altitude (according to parameters determined by the pilot). Another example of decision-taking information systems is found in modem factory production. In automobile production, continuous inventories of parts are maintained by computer as cars move down an assembly line. Orders are placed automatically by the computer when additional parts are needed. This is done without the intervention of a manager.

\section{OVERVIEW OF ORGANIZATION}

Birla Corporation Limited has number of plants, out of which, two at Satna (M.P.) - Satna Cement Works \& Birla Vikas Cement, Chanderia (Rajastan) - Birla Cement Works \& Chanderia Cement Works, and Durgapur (W.B) - Durgapur Cement Works \& Durga Hitech Cement and one at Raebareli (U.P). They manufacture varieties of cement like Ordinary Portland Cement (OPC), 43 \& 53 grades, Portland Pozzolana Cement (PPC), Fly Ash - based PPC, Low Alkali Portland Cement, Portland Slag Cement, Low Heat Cement and Sulphate Resistant Cement. The total employees in the plant are found around 5200 of various categories. The system developed is used to maintain attendance record for the same. [8]

\subsection{Designing of MIS for Attendance} Capturing \& Recording System

The main objective of Attendance Recording System (ARS) is to ensure that the attendance (i.e. presence or absence) of employees is accurately recorded and reported for computation of payable days, overtime hours, festival allowances and payable ESI contributions etc.

\subsection{Responsibilities}

Following are the responsibilities assigned at various levels in the organization-

1. Employing Activity's Responsibilities

2. Approving official's Responsibility

3. Timekeeping Responsibilities

An efficient employee Attendance Recording system makes for a smoother-running organization. The ARS can contribute to an organization's overall harmony and efficiency. This automated system saves time for managers and employees, improving their productivity. By eliminating manual record keeping, it reduces errors, avoiding disputes. ARS integrates a company's accrual policies and consistent awarding of employee attendance.

\subsection{Decision Making at Top Level}

A decision is basically resource allocation process that is irreversible except that a fresh decision may reverse it or it may overrule the earlier one. A decision is a reasoned choice among alternatives. The decision maker having authority over the resources being allocated makes a decision. The decision can be of various types like simple decision in which there is only one decision is to be made with many alternatives, decision may be goal oriented; decision may be strategic or tactical. The decision capacity involves intelligence, design, choice and implementation of decision maker. 
The MIS designed in the study for Attendance Capturing \& Recording for Birla Corporation Limited mainly generates the reports like Daily Attendance, Monthly Attendance, Sick Report etc. on which the top management by receiving these reports analyses and the decisions regarding shifting the priority of the job, observing the performance and corrective measures are taken.

\subsection{MIS Designed for Attendance Capturing \& Recording System}

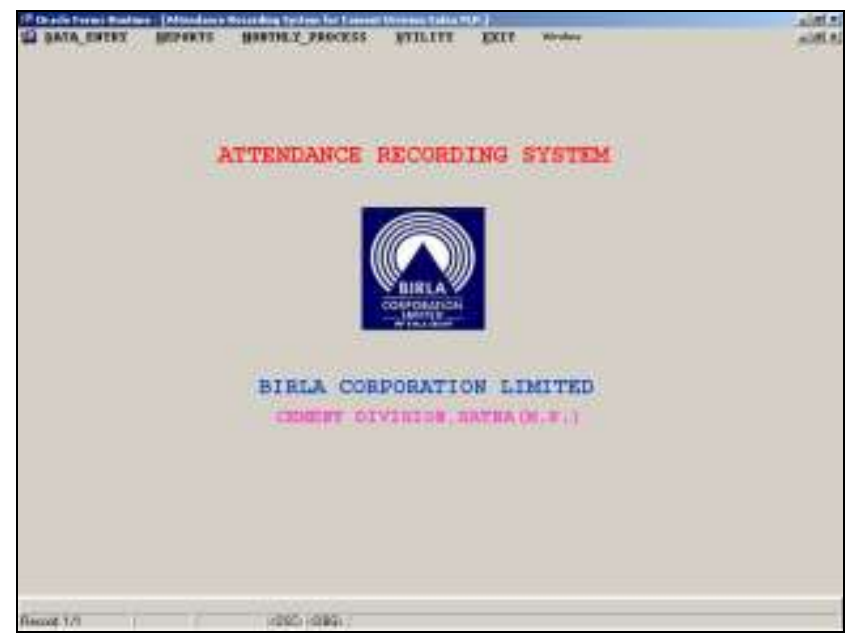

\subsection{Reporting from the Designed MIS}

The reports which are used by top management are generated from the above MIS like Monthly Attendance, Card Replacement, Sick Report, and Monthly Voucher Correction which are submitted to HR Manager and he takes proper decisions related with Attendance Capturing \& Recording.

\section{CONCLUSION}

The paper entitled 'MIS is an Effective Tool to Decision Making' gives an impact on the important function of top management. It is also used to generate the reports with the help of advanced technology having maximum characteristics of good information by which the decisions are to be taken related with the functionality of management decisions. The MIS model developed specifically helps HR managers to keep the control on working of the staff at various levels.

The system has been tested for above module in Birla Corporation Ltd. The Reports generated are as per the format by which it will help top management to take decision concerned with human resource in attendance recording and capturing which is one of the basic needs of any organization.

\section{COMMUNICATION TO SOCIETY}

The study proposed for research will contribute directly and indirectly to the society at large by following means:
1. The managers at top level and middle level will get prompt and timely reports from proposed MIS.

2. The employees will be continuously evaluated for quality and work culture.

3. Customers of the organization will get the benefits of the proposed system by the way of timely service, minimum cost and information related with their products.

4. Society at large will be benefited by using advance technology in managing the organization which will bring competitive environment in society.

\section{FUTURE SCOPE}

Management Information System is required for managerial report generation specialized tools; software and procedures are used to develop MIS in the organizations. In the future Decision Support Systems for a particular domain can be developed which can be used for decision support at top level management.

\section{ACKNOWLEDGMENTS}

The author acknowledges gratitude to Birla Corporation Limited for providing the support for this study without their cooperation it is difficult to develop the MIS model.

\section{REFERENCES}

[1] Annual Report of Birla Corporation Limited.

[2] Arora A., Management Information Systems, Himalaya Publishing House, Mumbai.

[3] Banerjee, U. K., \& Sachdeva, R. K. (1995). Management Information System: A new frame work. New Delhi: Vikas Publishing House.

[4] Davis, G.B., \& Olson, M. H. (1985). Management information systems: Conceptual foundations, structure, and development. New York: McGraw-Hill.

[5] Dr. Milind Oka (2009), Management Information Systems Text and Cases (16 ${ }^{\text {th }}$ ed.), Everest Publishing House, Pune.

[6] Gupta R. C., Management Information Systems, CBS Publishers \& Distributers, New Delhi.

[7] Jawadekar, W. S. 1998, Management Information System, Tata McGraw Hill Publishing Company Ltd. New Delhi.

[8] Lordon K. L., Management Information System, Prentice Hall of India, New Delhi.

[9] Lucas, H. C., Jr. (1990), Information systems concepts for management. New York: McGraw-Hill.

[10] McLeod, R., Jr. (1995). Management information systems: A study of computer-based information systems (6th ed.). New Delhi: Prentice Hall of India.

[11] Murthy C. S. V., Management Information Systems, Himalaya Publishing House, Mumbai.

[12] Waman S Jawadekar (2007), Management Information Systems Text and Cases ( ${ }^{\text {rd }}$ ed.), Tata McGraw Hill Publishing Company Ltd., New Delhi. 